\title{
O professor e a pesquisa: as experiências com a escrita na universidade
}

\author{
Victoria Wilson*
}

\begin{abstract}
Resumo
Fundamentado numa concepção etnográfico-discursiva (CORRÊA, 2011; 2013), em estudos de letramentos (STREET, 2004; 2010; 2014; GEE, 1994) e do discurso (BAKHTIN, 1993; 2003), o trabalho se inscreve no âmbito da Linguística Aplicada. Apresenta como objetivo geral a reflexão sobre os modos de apropriação do gênero acadêmico "projeto de monografia", no contexto de uma faculdade de formação de professores, considerando a perspectiva discursiva bakhtiniana, especialmente, a tensão entre as palavras de autoridade e a internamente persuasiva, discutindo a concepção de normatividade da língua. A escrita acadêmica é concebida como prática social e experiência subjetiva com a língua(gem) e está sujeita a fatores diversos que integram e modelam $\mathrm{o}(\mathrm{s})$ chamado(s) letramento(s) acadêmico(s). Através da análise de pequenos excertos de texto do gênero em pauta, procurou-se construir entendimentos acerca da complexidade da escrita acadêmica em um evento específico, colocando em cena os participantes: aluno, professorpesquisador, pesquisador-professor. A análise procurou mostrar como os alunos elaboram sua escrita capturando as normas do contexto e dos gêneros acadêmicos.
\end{abstract}

Palavras-chave: Letramentos. Escrita acadêmica. Gêneros acadêmicos. Ensino.

\section{The professor and the research: the writing experiences ate the university}

\begin{abstract}
Based on an ethnographic-discursive conception (CORREA, 2011; 2013), in the literacy (STREET, 2004; 2010; 2014; GEE, 1994) and discourse studies (BAKHTIN, 1993; 2003), the work is in the field of Applied Linguistics. The overall objective presented is the reflection on the modes of appropriation of the academic genre "monograph project", in a Faculty of Teacher Training context, considering the Bakhtinian discursive perspective, especially the tension between the words of authority and the internally persuasive, discussing the conception of normative language. Academic writing is conceived as a social practice and a subjective experience with the language and is subject to several factors that integrate and model the so-called academic(s) literacy (ies). Through the analysis of small excerpts of text of the genre in question, attempts have been made in order to construct understandings about the complexity of the academic writing in a specific event, staging the participants: student, professor-researcher, researcher-professor. The analysis sought to show how students write their writing by capturing the context and academic genres' standarts.
\end{abstract}

Keywords: Literacies. Academic writing. Academic genres. Teaching.

Recebido: 07/03/2019

Aceito: $12 / 07 / 2019$

\footnotetext{
* Universidade do Estado do Rio de Janeiro (UERJ). Doutora em Letras pela Pontifícia Universidade Católica do Rio de Janeiro. Pós-doutoramento na Universidade Federal Fluminense. Professora associada de Linguística do Departamento de Letras da Faculdade de Formação de Professores (FFP) da Universidade do Estado do Rio de Janeiro (UERJ), na graduação, na pós-graduação lato sensu (Especialização em Ensino de Língua e Literaturas) e nos Programas de Mestrado Profissionalizante em Letras (PROFLETRAS) e em Letras e Linguística (PPLIN).
} 


\section{Introdução}

Este trabalho discute aspectos relacionados ao letramento acadêmico, a partir de textos produzidos por alunos de graduação em Letras de uma instituição pública de formação de professores, localizada em um município da periferia da cidade do Rio de Janeiro, no Brasil. Escrever, ler e aprender na universidade é um desafio para os alunos, assim como para os professores, quanto à sua tarefa de ensinar.

A questão da escrita na universidade, mais exatamente, no processo da formação universitária, vem sendo abordada por diversos autores. No que concerne a este trabalho, as reflexões sobre letramento acadêmico ou práticas de escrita na universidade são oriundas de pesquisa desenvolvida sobre o assunto que busca compreender a apropriação e a aprendizagem dos gêneros acadêmicos pelos alunos, especialmente, os gêneros projeto de monografia e monografia.

O trabalho se inscreve no âmbito da Linguística Aplicada e tem como objetivo refletir sobre as habilidades dos alunos na apropriação do gênero acadêmico em tensão com as práticas sociais da escrita, isto é, os movimentos da escrita em termos da expressão das palavras de autoridade e internamente persuasiva, conforme Bakhtin (1993). Compreender essas práticas e seus sentidos é essencial para compreender os efeitos do ensino e da aprendizagem dos gêneros acadêmicos na universidade para repensar continuamente o letramento em sua perspectiva ideológica, isto é, no sentido predominante de práticas sociais, no âmbito dos Novos Estudos do Letramento.

As razões que justificam esse estudo estão centradas na compreensão dos diferentes modos de ser letrado na academia e nos impactos e nas repercussões em termos da legibilidade e legitimidade da produção escrita dos alunos, uma vez que a apropriação dos gêneros acadêmicos não ocorre de modo linear nem uniforme, pois é dependente de vários fatores, tais como: a própria experiência do aluno com as diferentes modalidades de gêneros e linguagens; o letramento escolar (anterior ao ingresso na universidade), que pode favorecer ou não a aprendizagem de outros gêneros; a motivação para a escrita vinculada à sua finalidade acadêmica, institucional (para que se escreve na universidade), e a sua função social mais amplificada (os efeitos da aprendizagem da escrita acadêmica na vida profissional futura); as dificuldades particulares em relação aos diferentes gêneros acadêmicos e suas linguagens - modos de dizer - em face das distintas esferas de conhecimento; a prática de escrita de textos acadêmicos desenvolvidas e estimuladas pelos professores em suas aulas; a sensibilidade e a expectativa dos professores diante das dificuldades dos alunos, dentre outros fatores.

As perguntas que norteiam a presente pesquisa buscam refletir sobre: (i) os indícios que se revelam nos textos em termos de apropriação de práticas de letramento e que se tornam relevantes para a compreensão do letramento acadêmico na universidade; (ii) os desafios impostos ao professor/ pesquisador na função de leitor/avaliador das produções dos alunos; (iii) a importância da escrita e sua prática na universidade no processo de formação profissional de futuros professores de língua(s).

A partir dessas considerações, destacamos que a experiência com a língua(gem) é única, pois subjetiva, segundo Cameron (2003), afetando e repercutindo (n)os diferentes modos de ser letrado; além do que, no processo de sua socialização acadêmica, as pessoas procuram encontrar e dar sentido à sua experiência (ZAVALA, 2010), conforme se pretende mostrar nas seções a seguir.

\section{Práticas de escrita na universidade: orientações teórico-metodológicas}

A pesquisa aqui descrita é de natureza qualitativa e interpretativista e está fundamentada no princípio da heterocientificidade, perspectiva bakhtiniana para tratamento do objeto das ciências humanas: o ser expressivo e falante (BAKHTIN, 2003). Uma vez que a análise do material parte da leitura e 
observação dos modos de apropriação de linguagens e conhecimentos pelos alunos por meio de e com a produção escrita do gênero projeto, buscou-se também fundamentação no paradigma indiciário (GINZBURG, 1989) e na pesquisa etnográfico-discursiva (CORRÊA, 2011). Segundo o paradigma indiciário, a busca por indícios, sinais ou vestígios não é determinada a priori, e sim à medida que o pesquisador se abre à "leitura" sensível para pequenos detalhes, aparentemente sem importância ou insignificantes. Nesse sentido, o trabalho etnográfico-discursivo torna-se aliado-chave, pois o discurso se destaca como elemento estruturador-estruturante das relações ensino-aprendizagem, contribuindo para uma análise que se propõe a colocar em relevo pequenos detalhes que podem ser reveladores das tensões, contradições, imprecisões e conflitos (ou não) que se desencadeiam na constituição do letramento acadêmico (CORRÊA, 2011).

Este trabalho, pois, se insere em práticas de letramento que registram os modos como alunos do curso de Letras elaboram a sua escrita em aulas de "Projeto de Monografia" (eventos de letramento, na concepção de Barton, 2000) e o que projetam em seus textos em termos de linguagens e conhecimentos especializados no contexto de uma faculdade de formação de professores. ${ }^{1} \mathrm{O}$ material de análise deste trabalho, portanto, é fruto desse processo, em sua versão final, e das práticas de letramento dos alunos ao longo dessa disciplina. ${ }^{2}$

As aulas de Projeto de Monografia integram o componente curricular dos cursos PortuguêsLiteraturas e Português-Inglês do Departamento de Letras da Faculdade de Formação de Professores. Concebida à época da primeira reforma curricular por que passou a unidade, no ano de 2006, a criação da disciplina tinha como objetivo introduzir o aluno na redação de seu projeto de monografia, com a finalidade de auxiliá-lo na etapa posterior, ou seja, a elaboração da monografia, que constitui o chamado Trabalho de Conclusão de Curso, introduzido nessa referida reforma. A disciplina prevê dois tempos de aula semanais, é oferecida no sétimo período do curso e é ministrada por um professor cuja função é a de ensinar os processos de elaboração do gênero projeto acadêmico. ${ }^{3}$ Além dessa disciplina, o departamento oferece duas outras também voltadas para a elaboração de textos acadêmicos, tais como resenhas, relatórios, textos argumentativos de natureza científica, em geral, oferecidas no início do curso. No que se refere ao desenho das aulas que será aqui descrito, convém esclarecer que se trata de experiências por mim vividas como docente dessa disciplina, uma vez que a dinâmica das aulas fica a critério do professor responsável pela disciplina.

As aulas são planejadas em três momentos. No primeiro, são compartilhadas informações gerais sobre a organização e funcionamento do curso e orientações acerca das particularidades do gênero, seguindo-se a apresentação das metodologias de pesquisa, com indicação bibliográfica específica. Nessas aulas, primeiramente, ao aluno é solicitada a escolha da área da pesquisa e do tema a ser desenvolvido para procurar seus respectivos orientadores, ficando a cargo do professor da disciplina acompanhar o passo a passo da elaboração dos projetos, "administrar" (ler e reler) os usos da escrita durante esse processo e os seus desdobramentos até a fase final. Após a escolha da área e do tema da pesquisa, introduz-se a explicação de cada item do projeto, destacando os modos de dizer e o os modos de fazer: o objeto e o problema da pesquisa; os objetivos (geral e específicos); as hipóteses (de acordo com a área, a abordagem e a orientação do professor-orientador); a justificativa (com destaque para a relevância da pesquisa, chamando a atenção dos alunos para o seu interesse e motivação pessoal em relação ao tema e ao objeto da pesquisa, bem como a preocupação acadêmico-profissional em relação ao trabalho que será desenvolvido).

Em seguida, tendo em vista as dificuldades dos alunos relativas à escrita acadêmica e, especialmente, em relação ao gênero projeto, passa-se ao segundo momento das aulas, em que se propõe uma

1 A instituição localiza-se no município de São Gonçalo e está integrada à Universidade do Estado do Rio de Janeiro.

2 Os projetos são cedidos pelos alunos para a pesquisa.

3 Em vias de uma nova reforma curricular, a referida disciplina será extinta, mas o gênero será trabalhado nas disciplinas dedicadas à elaboração de textos acadêmicos, com carga horária ampliada, e o trabalho final do curso compreenderá outras produções acadêmicas além da monografia. 
dinâmica menos expositiva e menos teórica, privilegiando as ações, isto é, o trabalho com a escrita dos projetos. ${ }^{4}$ As aulas, desse modo, mudam de estilo, assumindo o formato do tipo "oficinas de produção de texto". Nesse momento, cada aluno (em geral, o Departamento estabelece o número de 15 alunos por turma nas aulas de Projeto de Monografia) é convidado a apresentar aos demais colegas cada item do projeto, itens previamente estabelecidos para serem expostos oralmente na sequência semanal das aulas. Dessa forma, dificuldades, conflitos e também soluções podem ser compartilhadas e vividas coletivamente, servindo de estímulo àqueles que se sentem mais desorientados na busca até mesmo do tema da pesquisa. ${ }^{5}$ Nessa fase, discutimos e confrontamos tudo, desde o tema, passando pelas hipóteses (e sua problematização), pelo problema e motivação da pesquisa até os objetivos (sua formulação escrita, o "como dizer" e sua pertinência, "por que" e "para que dizer").

À medida que os alunos vão avançando no desenvolvimento do projeto, conseguindo ultrapassar as dificuldades iniciais já citadas, a dinâmica da aula sofre nova alteração. O "estilo" oficina é mantido, porém alternando-se momentos coletivos com atendimentos individuais. Passa-se, então, ao terceiro momento, fazendo-se comentários exclusivos com cada aluno (ainda que esses comentários possam ser posteriormente compartilhados, toda vez que se observa que o problema ou a questão podem ser do interesse de todos por constituírem dúvida recorrentemente constatada, por exemplo). Naturalmente, esta torna-se a fase mais trabalhosa das aulas, pois tem início o processo de leitura e releitura, ajustes e correções, de revisão e reescrita dos textos por mim e pelos alunos, aula a aula, até o final do semestre. Trata-se de um momento "duro" para os alunos e também para o professor, porém o mais enriquecedor, pois se trata, de fato, do momento em que é possível observar as atividades e práticas de letramento dos alunos em seu processo de aprendizagem. Esse processo, em geral, consome os dois meses finais do curso até o seu término. Com dois tempos semanais de aula e estabelecendo uma dinâmica de oficina de texto, alguns ajustes se fazem necessários a fim de que os alunos sejam atendidos. Para atingir esse objetivo: (i) dedico mais uma hora de aula, além do meu horário, com alunos que têm disponibilidade para esse fim; (ii) alterno o número de alunos por semana, de modo que todos possam ser atendidos satisfatoriamente, já que nem todos conseguem cumprir os prazos semanais estabelecidos para o cumprimento de metas predeterminadas por mim. Assim, chegamos ao último dia do curso com todos os projetos prontos, lidos e revisados.

Alternam-se, pois, os papéis: de professor-pesquisador a pesquisador-professor. O que muda quando se muda a perspectiva? Não se trata de tarefa simples passar agora à análise e compreensão das práticas letradas, cujos eixos da investigação estão orientados para a observação dos modos como os alunos fazem uso da língua escrita acadêmica e a internalizam; como se mostram e se expressam como aprendizes no contexto acadêmico. Nessa ótica, um dos desafios desse trabalho, é o de "desfazer princípios, crenças, mal-entendidos que sustentam e propiciam uma relação 'tímida', 'deficiente', 'inadequada' dos nossos alunos com as práticas acadêmicas sustentadas pela escrita" (MARINHO, 2010, p. 372), para entendê-las como mais um modo de experimentar a língua e os gêneros, uma vez que, nos processos de aprendizagem da escrita, em contextos institucionais (como a escola e a universidade), "sua apropriação afeta subjetivamente os alunos" (GOULART, 2014, p. 40), e, assim, tanto o contexto como as suas convenções são alterados por essas relações.

A experiência subjetiva com a língua (a linguagem) assume um destaque especial, neste trabalho, por discutir a concepção de normatividade da língua, "higiene verbal”, segundo Cameron (2003),

4 Sobre as dificuldades dos alunos, trata-se daquelas relativas à escrita acadêmica, ao estilo do gênero, compreendendo-as no âmbito do contexto acadêmico, não devendo ser consideradas como dificuldades inerentes ou resultado de letramentos escolares anteriores. Portanto, precisam ser ensinadas para serem aprendidas.

5 Cabe ressaltar que alunos já inseridos em projetos de pesquisa, como bolsistas de Iniciação Científica, Iniciação à Docência, entre outras modalidades de bolsa, em geral, apresentam menos dificuldade em relação à elaboração do projeto, pelo menos no que tange à sua concepção, mas não necessariamente em relação à fluidez da escrita. Evidentemente, o envolvimento com o objeto da pesquisa, com as atividades de leitura e a participação em eventos acadêmicos são fatores que atuam na familiarização e desinibição dos alunos com as práticas e eventos de letramento, facilitando a apropriação dos gêneros acadêmicos. 
e trazê-la para o centro das reflexões sobre letramento acadêmico. A higiene verbal é tratada como fenômeno geral que regula as línguas, só existindo em práticas específicas, socialmente situadas e historicamente encaixadas. Conforme a autora, a higiene verbal opera com vários tipos de ordem na e da língua, dentre as quais a ordem moral, social e política (CAMERON, 2003). Segundo essa mesma autora, todos (gramáticos e linguistas, cada um a seu modo) somos, de um modo ou de outro, higienistas verbais devido às nossas experiências linguísticas e discursivas, das quais não conseguimos abrir mão, pois são constituintes de nossas identidades. Então, como lidar, no contexto acadêmico e no âmbito das pesquisas sobre letramentos, com outras ordens e outras experiências quando diferentes das nossas, das previsíveis pelos contextos? Para Cameron:

No caso do uso da língua, pode se argumentar que o investimento na autoridade tradicional manifesta não só uma preferência geral pela continuidade em detrimento da mudança, mas também um apego a valores e práticas que foram inscritos nas pessoas nos estágios formativos de suas histórias linguísticas particulares. [...] dominar qualquer habilidade complexa e difícil dá à pessoa um estímulo inerente a defender suas práticas. Se eu investi tanto tempo e esforço aprendendo a escrever de acordo com um conjunto particular de prescrições, vou custar a me convencer de que tais prescrições não são necessárias e desejáveis; admitir que as regras são arbitrárias e infundadas é desvalorizar o meu próprio sucesso em dominá-las. Além disso, ao final de meu aprendizado, eu provavelmente terei internalizado certas normas em tal medida que não sou mais capaz de senti-las como arbitrárias, ainda que intelectualmente eu saiba perfeitamente que elas o são. (CAMERON, 2003, p. 13).

Nesse sentido, a autora argumenta o quanto a normatividade é um elemento que integra as práticas e experiências com a língua, sendo uma parte importante "do que significa usar a língua e não apenas alguma coisa perversamente 'enxertada nela"” (CAMERON, 2003, p. 1). É nesse aspecto que observamos uma possibilidade de aproximação com o modelo ideológico concebido por Street (2004), no sentido de entender que a normatividade é o que as pessoas (e os alunos) capturam, internalizando, quando precisam escrever de acordo com normas (outras), no caso, tão peculiares quanto as do gênero acadêmico projeto de monografia. Afirma Cameron que:

A capacidade humana de adquirir e usar a língua é necessariamente tornada real dentro das relações sociais. Assim, o tipo de regularidade comportamental capturada numa regra tem de surgir, sem dúvida, em primeiro lugar, do fato de os falantes aprenderem e seguirem certas normas. (CAMERON, 2003, p. 15).

Tais normas então: (i) são atravessadas pelas nossas experiências linguísticas e discursivas passadas, presentes e projetadas para o futuro, de acordo com os destinatários; (ii) não correspondem ao sistema abstrato de regras e às estruturas isoladas das línguas; ao contrário, naturalizam-se nas práticas cotidianas e são criadas e recriadas ou elaboradas e reelaboradas nos contextos reais, dentro das comunidades de práticas e ali são sentidas como deslocadas ou próprias. A normatividade, como elemento constituinte da língua, será concebida então em sua dimensão reguladora, histórica e socialmente situada, como componente integrante e integrador das experiências subjetivas dos participantes do processo de ensino e de aprendizagem (professores e alunos), em busca de possíveis e prováveis padrões de letramento.

A academia, em seu impulso homogeneizador/higienizador, como contexto altamente regularizador de práticas letradas situadas, produz, elabora e "mantém" determinados usos e padrões linguísticos, prototípicos de suas práticas internas e de seus eventos particulares, atuando, nesse caso, como "palavra de autoridade", exercendo uma força centrípeta (BAKHTIN, 1993) sobre os modos de apropriação das linguagens (letramentos) pelos alunos. Porém, o modo como cada indivíduo se "apodera" da língua, nesse ou em outros espaços e nos eventos acadêmicos, revela também certas 
singularidades, isto é, o modo como cada um vive a experiência com o trabalho, a prática linguísticodiscursiva. Apesar das práticas e forças coercitivas e controladoras "inerentes" ao contexto e aos gêneros acadêmicos, estes também são refratários a mudanças, porque estão sujeitos ao dinamismo e ao dialogismo entre as forças centrípetas e centrífugas (BAKHTIN, 1993) e às modulações humanas que os tornam semioticamente heterogêneos: "na prática viva da língua, a consciência linguística do locutor e do receptor nada tem a ver com um sistema abstrato de formas normativas, mas apenas com a linguagem no sentido dos contextos possíveis de uso de cada forma particular." (BAKHTIN; VOLOCHÍNOV, 1988, p. 95).

$\mathrm{Na}$ (re)construção dos chamados saber e dizer científicos, é necessário que o aluno elabore uma série de operações e ações cognitivas, bem como pragmáticas e sociocomunicativas, porém não basta aprender, segundo Marinho (2010, p. 372) “(e principalmente treinar) um conjunto de estratégias textuais, de conteúdos gramaticais, de regras e convenções típicas do texto acadêmico, para que as [essas] dificuldades sejam resolvidas" (MARINHO, 2010, p. 372), porque a participação na cultura discursiva, na comunidade de prática, sem dúvida, é um componente forte para a produção da aprendizagem. O deslocamento dos gêneros do cotidiano para a escola ou universidade provoca outros deslocamentos, colocando em "confronto as formas do dialogismo próprias de cada gênero e de cada texto e as formas de recepção da palavra na escola [academia]" (ROJO, 2008, p. 96).

Portanto, abordar os usos institucionais da escrita e compreendê-los como processos construídos no contexto acadêmico impulsiona o olhar e a compreensão para outros modos de lidar com as práticas de letramento e suas implicações didático-pedagógicas, suas repercussões no ensino:

[...] caberia à academia (re)orientar suas práticas de letramento acadêmico a fim de contribuir para uma formação que fortaleça professores em seu processo formativo, inclusive fornecendo-lhes a base para formação dos alunos da educação básica na perspectiva dos novos letramentos. (VIANNA et al., 2016, p. 51).

\section{As práticas de letramento: a experiência dos alunos com o texto escrito}

O material analisado no presente artigo constitui-se de excertos dos projetos de monografias produzidos pelos alunos nas aulas de Projeto de Monografia. Os textos foram cedidos pelos alunos para a pesquisa e são identificados com a primeira letra do nome de cada um. São projetos realizados em duas áreas: Linguística e Literatura.

Para a análise, foram selecionados alguns excertos referentes à introdução e à fundamentação teórica para serem interpretados com base nos conceitos de "palavra de autoridade" e "palavra ideológica do outro internamente persuasiva". Conforme propõe Bakhtin, a palavra autoritária "não se representa - ela é apenas transmitida"; não é livre para realizar alterações estilísticas; "não pode ser essencialmente bivocal"; pode encarnar "conteúdos diferentes (o autoritarismo como tal, a autoridade, o tradicionalismo, o universalismo, o oficialismo e outros)" (BAKHTIN, 1993, p. 144145); a palavra ideológica do outro internamente persuasiva é "determinante para o processo de transformação ideológica da consciência individual”; esta palavra é dialógica, pois, "no processo de assimilação positiva, se entrelaça estreitamente com a "nossa palavra"” (BAKHTIN, 1993, p. 145).

Com base nas concepções das palavras de autoridade e ideológicas (internamente persuasivas), encontramos, na leitura dos projetos, os modos de apropriação do discurso alheio pelos alunos. Entendemos como discurso alheio o referencial teórico, as vozes do professor e as do orientador com os quais os alunos fundamentam seu discurso, e o estilo como o modo segundo o qual essa apropriação se realiza. Convém destacar, de acordo com Bakhtin (2003, p. 302), como "a posição social, o título e o peso do destinatário refletidos nos enunciados dos campos cotidianos e oficiais", 
[acrescentam-se os científicos] sempre levam em conta o "fundo aperceptível da percepção do meu discurso pelo destinatário". Para o autor, “[...] essa consideração irá determinar também a escolha do gênero do enunciado e a escolha dos procedimentos composicionais e, por último, dos meios linguísticos, isto é, o estilo do enunciado" (BAKHTIN, 2003, p. 302).

Incialmente, apresentaremos os excertos destacados de três projetos do campo da Linguística Funcional.

\begin{tabular}{|c|c|c|}
\hline Projeto 1 - (L.A.S.) & Projeto 2 - (E.M.S.) & Projeto 3 - (L.D.S.) \\
\hline Introdução & Introdução & Introdução \\
\hline $\begin{array}{l}\text { A presente pesquisa busca investigar } \\
\text { o resultado da mudança categorial } \\
\text { sofrida pelo item olha no Português } \\
\text { Brasileiro. De acordo com os nossos } \\
\text { estudos, este item passou por um } \\
\text { processo de gramaticalização, } \\
\text { afastando-se da sua função verbal } \\
\text { de orientador do olhar, chegando a } \\
\text { uma nova, a de marcador discursivo } \\
\text { sequenciador e interacional. } \\
\text { Conforme podemos atestar nos } \\
\text { exemplos como: "o que eu sei fazer? } \\
\text { Olha.. eu sei fazer muita coisa... mas } \\
\text { uma das coisas que eu sei... gosto de } \\
\text { fazer é lasanha..., né? [...]." }\end{array}$ & $\begin{array}{l}\text { O caráter fluido das línguas naturais } \\
\text { tem motivado um grande número de } \\
\text { pesquisas em diferentes vertentes } \\
\text { da Linguística. Tendo em vista a } \\
\text { estrutura maleável da língua, o } \\
\text { presente trabalho traz reflexões sobre } \\
\text { a mudança linguística, à luz dos } \\
\text { estudos da Linguística Funcional, } \\
\text { teoria que se ocupa em estudar } \\
\text { a língua a partir de seus usos em } \\
\text { situações comunicativas reais. [...]. }\end{array}$ & $\begin{array}{l}\text { O presente trabalho consiste na } \\
\text { investigação do uso feito pelos } \\
\text { falantes de língua portuguesa do } \\
\text { verbo "ver" — originalmente de } \\
\text { percepção visual — como marcador } \\
\text { discursivo (MD), conforme atestamos } \\
\text { em: "Doc: Que é que você acha da } \\
\text { roupa que elas compram? [...] Loc: } \\
\text { Eu acho linda, eu acho uma beleza! } \\
\text { Francamente, eu acho maravilhosa, } \\
\text { viu?" (NURC: DID 0233). }\end{array}$ \\
\hline Fundamentação teórica & & Fundamentação teórica \\
\hline $\begin{array}{l}\text { O Funcionalismo Linguístico } \\
\text { contemporâneo entende a língua como } \\
\text { instrumento de interação social e "seu } \\
\text { interesse de investigação linguística } \\
\text { vai além da estrutura gramatical, } \\
\text { buscando no contexto discursivo } \\
\text { motivação para fatos da língua". } \\
\text { (CUNHA, COSTA \& CEZARIO, } \\
2015 \text {, p. 21). É pautada nessa visão } \\
\text { funcionalista que a presente pesquisa } \\
\text { se desenvolve, procurando nas cenas } \\
\text { comunicativas causas que levaram os } \\
\text { falantes a criarem uma nova função } \\
\text { para uma forma já existente. [...]. }\end{array}$ & $\begin{array}{l}\text { [...] A Linguística Funcional entende } \\
\text { a língua como uma atividade } \\
\text { comunicativa e, sendo assim, ela } \\
\text { não deve ser analisada como uma } \\
\text { estrutura independente das situações } \\
\text { de uso. Portanto, "segundo a hipótese } \\
\text { funcionalista, a estrutura gramatical } \\
\text { depende do uso que se faz da língua", } \\
\text { por isso, "a estrutura é uma variável } \\
\text { dependente, pois os usos da língua, } \\
\text { ao longo do tempo, é o que dão forma } \\
\text { ao sistema" (Furtado da Cunha, Costa } \\
\text { e Cezario, 2015, p. 21). Através } \\
\text { dessa concepção, os princípios } \\
\text { funcionalistas norteiam o estudo aqui } \\
\text { apresentado. [...]. }\end{array}$ & $\begin{array}{l}\text { Para o desenvolvimento deste } \\
\text { trabalho, baseamo-nos na teoria do } \\
\text { Funcionalismo Linguístico, segundo } \\
\text { o qual a gramática de uma língua não é } \\
\text { estática ou concluída. De acordo com } \\
\text { Furtado da Cunha (2012) [segue-se } \\
\text { uma longa citação da referida autora]. } \\
\text { Em oposição à concepção formalista, } \\
\text { segundo a qual a organização da } \\
\text { língua é motivada por aspectos } \\
\text { inerentes a sua própria estrutura, o } \\
\text { funcionalismo concebe a língua a } \\
\text { partir das funções comunicativas a } \\
\text { que serve, levando em consideração } \\
\text { os interlocutores, suas intenções e o } \\
\text { contexto discursivo. [...]. }\end{array}$ \\
\hline
\end{tabular}

Em relação aos excertos dos três projetos acima, fica nítido como os alunos se apropriaram da teoria funcionalista, seja reproduzindo a palavra de autoridade, seja se encaminhando para a palavra internamente persuasiva, tomando, em algumas partes do texto, a palavra outra como própria.

Ponzio, ao discutir o sentido da palavra reportada em Bakhtin, diz o seguinte: 
Diferentemente da coisa e da frase, a palavra outra tem sentido em si mesma, "por conta própria", além daquele que pode dar-lhe a palavra que a reporta; e esta, com o seu sentido, passa inevitavelmente a fazer parte da palavra de que fala, como elemento constitutivo da sua mesma construção sintática. (PONZIO, 2011, p. 30).

A interpretação é a de que, no processo de leitura dos textos teóricos, das conversas com o orientador, os alunos aprendem a e como se referir ao conhecimento teórico em que a palavra outra ora é assimilada com autorização (referência à fonte), ora é tomada como própria, livre. O sentido da palavra outra, em relação ao sentido da palavra que a reporta, apresenta-se seguindo duas tendências nesses recortes: a primeira parece coincidir com a palavra outra, em adesão à palavra de autoridade na transposição do discurso alheio, sugerindo uma regularidade em termos do estilo do gênero; porém, a apropriação individual revelou uma "relação de interferência" (PONZIO, 2011, p. 30), ainda que visível e elevada, mas com determinadas nuances de estilo que demonstram como os modos de recepção da palavra outra são sentidos, experimentados de acordo com a linguagem especializada, recursos lexicais e fraseológicos mais prototípicos da esfera funcionalista.

Passemos a mais três exemplos de projetos referentes à área da Literatura.

\begin{tabular}{|c|c|c|}
\hline Projeto 4 - (L.Z.C.V.) & Projeto 5 - (M.E.S.S.) & Projeto 6 - (C.S.G.) \\
\hline Introdução & Introdução & Introdução \\
\hline $\begin{array}{l}\text { Este trabalho é fruto das atividades } \\
\text { desenvolvidas durante meu período } \\
\text { como monitora da professora Iza } \\
\text { Quelhas na disciplina Literatura } \\
\text { Brasileira II (A prosa de ficção e o } \\
\text { teatro do século XX), que consiste } \\
\text { em analisar a obra As vítimas } \\
\text { algozes: quadros da escravidão, } \\
\text { de Joaquim Manoel de Macedo, } \\
\text { observando características do saber } \\
\text { e do poder das personagens contidas } \\
\text { no romance. Tal perspectiva implica } \\
\text { a problematização da figura do negro } \\
\text { escravo, do sistema escravocrata e a } \\
\text { dupla face da escravidão que fazem } \\
\text { do escravizado tanto vítima quanto } \\
\text { algoz. [...]. }\end{array}$ & $\begin{array}{l}\text { Não há como negar a importância } \\
\text { da crônica para a evolução e (re) } \\
\text { criação da Literatura Brasileira. O } \\
\text { gênero cronístico é o berço de nossa } \\
\text { Literatura, representado inicialmente, } \\
\text { segundo Jorge de Sá (1985), pela } \\
\text { carta de Pero Vaz de Caminha } \\
\text { a el-rei D. Manoel, ao registrar } \\
\text { circunstancialmente - de forma } \\
\text { artística-seu contato com os índios. } \\
\text { O texto de Caminha, por exemplo, } \\
\text { é crônica no sentido histórico da } \\
\text { palavra e antecipa a existência } \\
\text { de uma historiografia nacional. } \\
\text { Inicialmente, o caráter de registrar o } \\
\text { circunstancial e a realidade social é } \\
\text { estabelecido como princípio básico } \\
\text { da crônica, elaborada pelos "cronistas } \\
\text { medievais" através da sequência } \\
\text { cronológica dos acontecimentos. } \\
\text { O gênero, porém, ultrapassou os } \\
\text { limites do que está nos cânones e } \\
\text { sofreu mudanças em seu percurso, } \\
\text { mas, somente a partir do século } \\
\text { XIX, conquista visibilidade no } \\
\text { momento em que o jornal torna-se } \\
\text { acessível, com o triunfo da imprensa, } \\
\text { e transforma-se em cultura de massa. } \\
\text { [..l. }\end{array}$ & $\begin{array}{l}\text { Um sinal de trânsito que se abre e } \\
\text { um carro que não se movimenta, } \\
\text { causando transtorno para motoristas } \\
\text { e pedestres que estão no local. Assim } \\
\text { se inicia Ensaio sobre a cegueira, } \\
\text { de José Saramago. Publicado em } \\
\text { 1995, o romance é, segundo Teresa } \\
\text { Cristina Cerdeira (1999, p. 288), } \\
\text { "uma parábola cruel da cegueira que } \\
\text { a humanidade ensaia há longo tempo, } \\
\text { sem se dar conta disso: 'cegos que } \\
\text { veem, cegos que, vendo, não veem'." } \\
\text { A obra tem como característica a } \\
\text { temática universal do homem, e a } \\
\text { cegueira pode ser interpretada como } \\
\text { uma metáfora para a condição do } \\
\text { homem na contemporaneidade, } \\
\text { numa sociedade pautada em tarefas } \\
\text { — capitalismo que gera a criação de } \\
\text { novas demandas - e não nas pessoas } \\
\text { que as fazem. O livro demonstra a } \\
\text { ausência de sensibilidade perante o } \\
\text { próximo, os problemas da sociedade, } \\
\text { o distanciamento e o egocentrismo. }\end{array}$ \\
\hline
\end{tabular}




\begin{tabular}{|c|c|c|}
\hline Fundamentação teórica & Fundamentação teórica & Fundamentação teórica \\
\hline $\begin{array}{l}\text { Partindo do pressuposto estabelecido } \\
\text { por Michel Foucault de que "não há } \\
\text { poder sem que se tenha estabelecido } \\
\text { um saber", serão apresentadas as } \\
\text { perspectivas de reconhecimento desse } \\
\text { suposto saber e consequentemente } \\
\text { do poder proveniente dele. Tendo } \\
\text { em vista a dualidade do caráter } \\
\text { escravocrata entre a opressão } \\
\text { e a vitimização, os indivíduos } \\
\text { escravizados revelam a dupla face } \\
\text { que envolve a circunstância em que } \\
\text { estão inseridos, sendo tanto vítimas } \\
\text { quanto algozes de si e dos outros. } \\
\text { De acordo com Foucault (1979), “O } \\
\text { saber constitui relações de poder”. } \\
\text { O conteúdo do conhecimento dos } \\
\text { escravos, seja ele proveniente de seu } \\
\text { lugar de origem, seja acumulado no } \\
\text { dia a dia e com a convivência dos } \\
\text { demais, vindo de além-mar enquanto } \\
\text { tradição etc., faz parte de um potente } \\
\text { e vasto campo problemático, o qual } \\
\text { não podemos negligenciar para } \\
\text { a realização de uma análise mais } \\
\text { profunda da complexa relação vítima/ } \\
\text { algoz. }\end{array}$ & $\begin{array}{l}\text { Nosso trabalho parte de uma } \\
\text { perspectiva historiográfica e de modo } \\
\text { desconstrutivo, já que toda e qualquer } \\
\text { obra está aberta a novas visões e } \\
\text { sujeita a possíveis modificações e } \\
\text { ressignificações. } \\
\text { Procuramos apoio em teóricos como } \\
\text { Jorge de Sá (2002), Antonio Candido } \\
\text { (1992), Massaud Moisés (1967) e } \\
\text { Silviano Santiago (2002). No que } \\
\text { tange à revisão historiográfica do } \\
\text { conceito de crônica, nos respaldamos } \\
\text { em Ribas (2013). } \\
\text { A crônica tem merecido hoje a devida } \\
\text { atenção por parte da crítica. Desde } \\
\text { seu nascimento literário no Brasil, } \\
\text { esta atingiu matrizes que ultrapassam } \\
\text { o que nos trazem os cânones. [...]. }\end{array}$ & $\begin{array}{l}\text { É recorrente que as obras literárias } \\
\text { canônicas apresentem suas } \\
\text { personagens femininas a partir de } \\
\text { estereótipos culturais que as colocam } \\
\text { em segundo plano: frágeis e indefesas, } \\
\text { incapazes de lidar com situações de } \\
\text { risco ou sedutoras ou imorais. No } \\
\text { Ensaio sobre a cegueira, entretanto, } \\
\text { isso não ocorre: existe um universo } \\
\text { em que o masculino exerce todas } \\
\text { as prerrogativas, mas as mulheres, } \\
\text { de forma notável, constroem e } \\
\text { ocupam seus espaços. Ainda que } \\
\text { o universo literário instituído por } \\
\text { Saramago compartilhe da concepção } \\
\text { falocêntrica da realidade, suas } \\
\text { personagens denunciam, em seus } \\
\text { pensamentos, atos e palavras, os } \\
\text { absurdos dessa dominação e tornam- } \\
\text { se sujeitos de sua própria libertação. }\end{array}$ \\
\hline
\end{tabular}

Os três exemplos acima mostram como os modos de apreensão do discurso de outrem esboçam movimentos distintos, contraditórios ou mesmo complementares em relação às práticas de letramentos acadêmicos. Ainda que se observe uma adesão ao estilo do gênero, percebe-se também como o campo do saber e a linguagem especializada da disciplina, somada ao distinto conteúdo temático, caminham para outras formas de conhecimento e, consequentemente, letramentos. Podemos afirmar com Bakhtin que: "A palavra alheia introduzida no contexto do discurso estabelece com o discurso que a enquadra não um contexto mecânico, mas uma amálgama química (no plano do sentido e da expressão)" (BAKHTIN, 1993, p.141), porque as expressões verbais, o discurso, se manifestam como compreensão ativo-responsiva.

Segundo Ponzio (2011, p. 25), "a relação entre enunciação e situação extraverbal não é de simples espelhamento, de simples representação e re-apresentação", o que mostra como os alunos dialogam com a palavra alheia de modo distinto em face da natureza e da orientação da disciplina ou das formas de recepção dos discursos no campo da Literatura. Provavelmente, as coerções do discurso científico estejam mais enraizadas em determinadas áreas da Linguística e, assim, orientem a percepção dos alunos para a manutenção de maior "unidade e irrepetibilidade" das enunciações. No campo da Literatura, por sua vez, o discurso científico encontra outras formas, outro estilo, orientando os alunos para um processo de maior liberdade estilística em relação ao gênero.

Enfim, em ambos os modelos de projetos aqui tomados como referência para a análise dos modos de apreensão da língua escrita - como o discurso científico e a linguagem especializada em determinado 
evento de letramento - podemos notar como os discursos dos alunos deixam entrever o quanto há de crenças, valores e normas linguísticas referentes a cada gênero, a cada esfera da comunicação verbal e do saber, todos orientando diferentes modos de dizer. Crenças, valores e normas constituem a higiene verbal, que, segundo Cameron (2003, p. 16), "tem o potencial de lançar luz sobre as relações entre língua, sociedade e identidade". Assim, na luta com a palavra (discurso e conhecimento) de outrem, surgem conflitos, tensões, frutos também das experiências subjetivas mútuas com as práticas de letramento: as do professor e as dos alunos.

Quanto aos exemplos citados, todos os projetos fazem referência explícita ao campo teórico ou aos autores, demonstrando como as regras já começaram a ser internalizadas e como são assumidas, apropriadas pelos alunos. De onde vêm as normas e através de que práticas concretas são apreendidas, internalizadas, negociadas ou repelidas, são questões pontuadas por Cameron (2003, p. 16) e dizem respeito às próprias práticas de letramento. Nesse caso, as distintas experiências dos alunos indicam como são produzidas e reproduzidas, no meio acadêmico, não de forma mecânica ou automática, mas esboçando como falar e escrever nesse contexto; e como as normas estão sujeitas, "no ensino das disciplinas verbais", às forças centrípetas e centrífugas da língua, bem como à força da palavra de autoridade ou à assunção da palavra ideológica interiormente persuasiva (BAKHTIN, 1993). Nossa hipótese sobre os modos de apreensão do discurso de outrem é a de que os campos do saber são indícios fortes de influência sobre o estilo, em que atuam as forças centrípetas, ainda que variações estilísticas se manifestem no encaminhamento da teoria e do objeto de pesquisa, pois, segundo Stubbs (2002, p. 120), "a aprendizagem de uma disciplina depende claramente da competência comunicativa de interpretar como a língua, falada e escrita, é convencionalmente usada naquela disciplina".

"Sabendo ler o discurso reportado", diz Ponzio (2011, p. 32), "ele nos informa não sobre processos psicológicos subjetivos, fortuitos e passageiros, mas sobre estáveis tendências sociais sedimentadas nas formas previstas por uma dada língua para reportar o discurso do outro". Diante dessa afirmação, é possível arriscar algumas interpretações: (i) o caráter polifônico confirma a articulação e o entrecruzamento entre vários saberes e dizeres, logo faz parte do processo de letramento; (ii) a lexicalização, lugar de observação da relação entre o sujeito e a linguagem, segundo Corrêa (2004), revela o dialogismo presente nos modos de apreensão da palavra outra; (iii) e, assim, definindo vários matizes de estilo dos gêneros apesar da coerção dos gêneros acadêmicos; (iv) e, de acordo, com cada tendência, as percepções e orientações também variam, mostrando relações de identidade e experiências subjetivas com a língua(gem).

\section{Considerações finais}

Procuramos, neste trabalho, discutir uma das questões propostas por Street (2010) ao se referir aos rumos do letramento (“onde isso vai dar"?), buscando responder ou, pelo menos, situar algumas de nossas indagações: Quais as finalidades e os resultados dos eventos de letramento em termos de seu ensino para a formação dos alunos em processo de formação docente? Para onde nos levam de fato? As respostas parecem incidir sobre as nossas práticas como professores-pesquisadores/pesquisadoresprofessores e o sentido que lhes atribuímos, explicitando os aspectos norteadores e normatizadores que envolvem os letramentos acadêmicos e que não devem ser concebidos como a parte perversa desse processo - como modelo autônomo desenraizado e isolado das práticas sociais.

Sobre a constatação das dificuldades em relação à escrita acadêmica enfrentadas pelos alunos e professores, é preciso destacar que:

(i) O letramento acadêmico deveria cumprir um papel crítico e não paliativo no ensino superior, o que implica combater os discursos de déficit acerca da falta de lógica e de racionalidade nos aprendizes (ZAVALA, 2010, p. 91); 
(ii) a importância do letramento acadêmico é inegável, mas não se sustenta quando ensinado, considerado e analisado, prioritariamente, sob a perspectiva autônoma do letramento;

(iii) "o domínio do letramento acadêmico não garante o domínio de outros conhecimentos específicos de que o docente precisará para a sua prática didática” (VIANNA et al., 2016, p. 51), o que requer compreensão e esforços contínuos por parte do professor em suas atividades didáticas, pedagógicas, considerando as "dificuldades" dos alunos em diferentes situações;

(iv) os saberes, articulados e expressos nos e pelos textos dos alunos (re)produzem os (outros) saberes que eles têm sobre e com a língua, sobre os seus conhecimentos de mundo e de sua realidade vivencial, identitária, marcada pelo entrecruzamento das histórias pessoais com outras histórias, o que implica uma reorientação pedagógica e conceitual por parte de professores e pesquisadores;

(vi) os usos da língua ligados à nossa experiência com eles podem ajudar a entender tanto os processos de aprendizagem da linguagem e da escrita pelos nossos alunos quanto o modo como ensinamos ao lidarmos com a "ideologia" e com as concepções acadêmicas de linguagem e de escrita.

Por fim, na realização de projetos de pesquisa, os alunos são confrontados com muitas demandas que requerem um grau elevado de reflexão, pesquisa e ação com a linguagem: pensar e recortar o objeto de estudo; traçar hipóteses e objetivos; apresentar a relevância do trabalho; desenvolver a fundamentação teórica, fazendo as articulações necessárias e adequadas; esboçar minimamente a metodologia do trabalho; e, somado a todos esses aspectos, trabalhar a linguagem, o estilo do gênero.

São muitos os aspectos a serem considerados e, ainda que não sejam escritos por especialistas, ainda que não representem ações que incidam direta e especificamente sobre a prática docente, com certeza, representam um modo de conceber o conhecimento e as linguagens a ele relacionadas (racionalidades científicas), contribuindo para a formação pessoal e profissional do professor em formação e revelando o quanto há de vida em cada enunciado (BAKHTIN, 2003).

\section{Referências}

BAKHTIN, Mikhail. Questões de literatura e de estética: a teoria do romance. Tradução de Aurora Fornoni Bernardini et al. São Paulo: UNESP, Hucitec, 1993.

BAKHTIN, Mikhail. Estética da criação verbal. Tradução de Paulo Bezerra. São Paulo: Martins Fontes, 2003.

BAKHTIN, Mikhail; VOLOCHÍNOV, Valentín. Marxismo e filosofia da linguagem. Tradução de Michel Lahud e Yara Frateschi Vieira. São Paulo: Hucitec, 1988.

BARTON, David; HAMILTON, Mary. Literacy practices. In: BARTON, David; HAMILTON, Mary; IVANIC, Roz. (Ed.). Situated literacies: reading and writing in context. London, New York: Routledge, 2000. p. 7-15.

CAMERON, Deborah. Higiene verbal. In: CAMERON, Deborah. On verbal hygiene. Tradução de Marcos Bagno. London: Routledge, 2003. p. 1-32.

CORRÊA, Manoel Luiz Gonçalves. O modo heterogêneo de constituição da escrita. São Paulo: Martins Fontes, 2004.

CORRÊA, Manoel Luiz Gonçalves. As perspectivas etnográfica e discursiva no ensino da escrita: o exemplo de textos de pré-universitários. Revista da ABRALIN, no especial, $2^{\mathrm{a}}$ parte, p. 333-356, 2011. Disponível em: <http://www.abralin.org/revista/RVE2/11v.pdf>. Acesso em: 15 set. 2016.

CORRÊA, Manoel Luiz Gonçalves. Bases teóricas para o ensino da escrita. Linguagem em (Dis) curso, Tubarão, Santa Catarina, v. 13, n. 3, p. 481-513, set./dez. 2013. 
GEE, J. P. Social Linguistics and Literacies: ideology in discourses. Bristol: The Falmer Press, 1994.

GINZBURG, Carlo. Sinais: raízes de um paradigma indiciário. In: GINZBURG, Carlo. Mitos, emblemas, sinais: morfologia e história. Tradução de Federico Carotti. São Paulo: Companhia das Letras, 1989. p. 143-180.

GOULART, Cecília. 2010: Cultura escrita e escola: letrar alfabetizando. In: MARINHO, Marildes. (org.). Cultura escrita e letramento. Belo Horizonte: Editora UFMG, 2010. p. 438-456.

GOULART, Cecília. O conceito de letramento em questão: por uma perspectiva discursiva da alfabetização. Bakhtiniana, São Paulo, v. 9, n. 2, p. 35-51, ago./dez. 2014.

MARINHO, Marildes. A escrita nas práticas de letramento acadêmico. Revista Brasileira de Linguística Aplicada, Belo Horizonte, v. 10, n. 2, p. 363-386, 2010.

PONZIO, Augusto. Problemas da sintaxe para uma linguística da escuta. In: PONZIO, Augusto. Bakhtin: palavra própria e palavra outra na sintaxe da enunciação. São Carlos: Pedro \& João Editores, 2011. p. 7-58.

ROJO, Roxane. Gêneros de discurso/texto como objeto de ensino de línguas: um retorno ao trivium? In: SIGNORINI, Inês (org.). [Re]discutir texto, gênero e discurso. São Paulo: Parábola Editorial, 2008. p. 73-108.

STREET, Brian. Los nuevos estudios de literacidad. In: ZAVALA, Virginia; NIÑO-MURCIA, Mercedes; AMES, Patricia (Eds.). Escritura y sociedad: nuevas perspectivas teóricas y etnográficas. Lima: Rede para el Desarrollo de las Ciencias Sociales em el Perú, 2004. p. 81-108.

STREET, Brian V. Os Novos Estudos do Letramento: histórico e perspectivas. In: MARINHO, Marildes; CARVALHO, Gilcinei Teodoro. (org.). Cultura escrita e letramento. Belo Horizonte: Editora UFMG, 2010. p.33-53.

STREET, Brian V. Letramentos sociais: abordagens críticas do letramento no desenvolvimento, na etnografia e na educação. São Paulo: Parábola, 2014.

STUBBS, Michael. A língua na educação. In: BAGNO, Marcos; GAGNÉ, Gilles; STUBBS, Michael. Língua materna: letramento, variação e ensino. São Paulo: Parábola, 2002. p. 85-162.

VIANNA, Carolina A. D. et al. Do letramento aos letramentos: desafios na aproximação entre letramento acadêmico e letramento do professor. In: KLEIMAN, Angela B.; ASSIS, Juliana A. (org.). Significados e ressignificações do letramento: desdobramentos de uma perspectiva sociocultural sobre a escrita. Campinas, SP: Mercado de Letras, 2016. p.27-62.

WILSON, Victoria; CARMO, Thalita. A. do. Usos da escrita: linguagens e saberes em contexto de formação de professores. In: CONGRESSO LATINO-AMERICANO DE FORMAÇÃO DE PROFESSORES DE LÍNGUAS, 6., abr. 2017. p. 852-863. Disponível em: < https://www.proceedings. blucher.com.br/article-details/usos-da-escrita-linguagens-e-saberes-em-contexto-de-formao-deprofessores-25526>.

ZAVALA, Virginia. Quem está dizendo isso?: letramento acadêmico, identidade e poder na educação superior. In: VOVIO, Claudia; SITO, Luanda; DE GRANDE, Paula. (org.). Letramentos: rupturas, deslocamentos e repercussões em pesquisas em linguística aplicada. Campinas, SP: Mercado de Letras, 2010. p. 71-98. 